\title{
Stunting Amongst Pakistani Children Under Five: Status of Knowledge, Attitude and Practice of Health Care Workers at Basic Health Units and Rural Health Centers in Raiwind, Lahore
}

\author{
Shamaila Zamir, ${ }^{1}$ Rabbiya Sarwar, ${ }^{1}$ Saleem Ahmed, ${ }^{1}$ Sundas Ali, ${ }^{1}$ Usman Tariq
}

\begin{abstract}
Background: One of the major public health problems amongst children of Pakistan is the lack of proper nutrition. Health care workers ( $\mathrm{HCWs}$ ) at the primary level have a pivotal role in promoting good nutrition, but they lack basic nutrition knowledge and competence to provide good nutrition counseling to their clients.

Objective: To assess the knowledge, attitude, and practice of health care workers regarding stunting in under-five children, at Basic Health Units and Rural Health Centers of Raiwind, Lahore.

Methodology: This was a cross-sectional descriptive study including all HCWs (15 doctors and 15 nurses) in the selected 3 Rural Health Centers (RHC) and 9 Basic Health Units (BHU) in Raiwind, Lahore, from March 2019 to March 2020. A structured questionnaire was used for assessing the Knowledge, Attitude, and Practice (KAP) of HCWs regarding stunting in children under five. Descriptive statistics were used to analyze data, P-values $(p \leq 0.05)$ were considered to see if the difference is statistically significant between doctors and nurses.

Results: The HCWs' mean percent score of doctors versus nurses, for knowledge related to major childhood illnesses, was $48 \pm 22$ vs $46 \pm 21$, common nutritional problems $35 \pm 19$ vs $26 \pm 16$, and nutritional assessment methods $22 \pm 12$ vs $42 \pm 23$, in children under 5 years was found to be suboptimal. The total mean percent score for HCWs practices regarding health education of mothers was below $50 \mathrm{i}$-e $46 \pm 16$ vs $40 \pm 18$ in doctors vs nurses. The practice regarding breastfeeding was higher $65 \pm 20$ in nurses. All the doctors and $11(73 \%)$ nurses reported correct practice regarding iron and folic acid supplementation to pregnant mothers.

Conclusion: Despite having a positive attitude towards stunting, HCWs' had suboptimal knowledge and practice score in most of the items.
\end{abstract}

Keywords: KAP, HCWs, PHC, Stunting, Nutrition, Assessment methods

Article Citation: Zamir S, Sarwar R, Ahmed S, Ali S, Tariq U. Stunting Amongst Pakistani Children Under Five: Status of Knowledge, Attitude and Practice of Health Care Workers at Basic Health Units and Rural Health Centers in Raiwind, Lahore. JSZMC 2021;12(3):22-27.

DOI: https://doi.org/10.47883/jszmc.v12i02

This Open Access Article in Journal of Sheikh Zayed Medical College is licensed under a Creative Commons Attribution- 4.0 International License(CC BY 4.0)

\section{Introduction}

Sound nutrition is essential for good health, mental and social development, especially in early childhood and the achievement of the Sustainable Development Goals. ${ }^{1}$ Malnutrition is a major public health concern in the world. Worldwide, $1 / 3$ of children under 5 are not growing well due to various types of malnutrition; stunting, wasting, and overweight. ${ }^{2}$ In 2019, 5.2 million children under five died, mostly from preventable causes. ${ }^{3}$ Globally, around $50 \%$ of all under-five deaths annually are caused by undernutrition. ${ }^{4}$

Stunting is the result of poor maternal nutrition before and throughout pregnancy, and repeated bouts of infection in early childhood. A stunted child never attains full possible height, and also suffers from stunted development of the brain, learning difficulties in school, and poverty. ${ }^{5}$ About 144 million children under 5 years $(21.3 \%)$ were stunted in 2019, the majority of them lived in Asia and Africa. ${ }^{2}$ Children malnutrition is a serious public health problem in Pakistan. The country did not show any impressive gains in achieving the Millennium Development Goals regarding maternal and child health. ${ }^{6}$ According to the 2018 Pakistan National Nutrition survey, $40.2 \%$ of children are stunted.

Stunting has multifactorial determinants which require efforts from both within and outside the health sector i.e. policy, health system, and health manpower. ${ }^{8}$ The first two years of a child's life are crucial for investing in child nutrition ensuring more productive and healthier populations. ${ }^{1}$ During this period, HCWs at the primary care level have a crucial role for the improvement, prevention, and control of malnutrition among children. ${ }^{9}$ However, HCWs have inadequate nutrition knowledge and skills to provide basic nutrition counseling to the caregivers on antenatal visits. World Health Organization

1.University College of Medicine and Dentistry (UCMD), Lahore, Pakistan.

Correspondence: Dr. Shamaila Zamir, Senior Demonstrator, University College of Medicine and Dentistry (UCMD), Lahore. Pakistan.

Email: shamaila.faisal@ucm.uol.edu.pk

Received: 16-09-2021

Published: $30-09-2021$ 
recommends the need for a strong in-service nutrition training package and continuing education workshops for antenatal care providers to address nutritional problems among pregnant women. ${ }^{10}$ Primary care infrastructure in Pakistan includes more than 5500 BHUs or RHCs, and other first-level care facilities. However, the delivery of PHC services at the BHUs and RHCs is below the expected level. The health status of the people can be improved by having integrated $\mathrm{PHC}$ services in Pakistan. ${ }^{11}$

The current study assessed the role of HCW ' KAP in managing poor nutritional status in children under five years of age. The findings of the study may be used to identify existing knowledge, attitudes, and practices gaps regarding stunting management. The objective of this study was to assess the knowledge, attitude, and practice of health care workers regarding stunting in underfive children, at Basic Health Units and Rural Health Centers of Raiwind, Lahore.

\section{Methodology}

A cross-sectional descriptive study was conducted from March 2019 to March 2020, in three RHCs and nine BHUs centers in Raiwind, Lahore. All Healthcare Care Workers (15 doctors and 15 nurses) from the selected 3 Rural Health Centers (RHC), and 9 Basic Health Units (BHU) centers in Raiwind, Lahore were included. All Primary Healthcare Centers (RHCs \& BHUs) that are located in Raiwind were taken as a study population. The study area Raiwind was chosen because of its geographical accessibility and feasibility. Data were collected using a pretested questionnaire in English for doctors and for nurses we used a questionnaire in Urdu for their better understanding. Data were analyzed with SPSS version 24. The questionnaire was designed to collect data about HCWs' socio-demographic information, and HCW's KAP domain including six items for measuring knowledge, seven items for attitude, and seven items for practice. A fivepoint Likert scale with a score range, 1-Strongly disagree, 2- Disagree, 3- Neutral, 4- Agree, 5Strongly agree, was used to assess HCWs' attitude towards stunting. For quantitative variables, mean percent and standard deviation were used while for qualitative variables percentages and numbers were used. Chi-square test for qualitative variables and independent sample t-test for quantitative variables were being used. P-values of $\leq 0.05$ were considered statistically significant. The mean percent score was calculated. Greater the scoring value, the better the level of HCWs' Knowledge, Attitude, and Practice. The researcher used 60 as a cutoff point to differentiate between optimal 60 and suboptimal $<60$. Ethical approval was sought from the Ethics Committee of the Hospital.

\section{Results}

Amongst the studied group, there were 50\% doctors and 50\% nurses from the designated BHU and RHC centers. Out of the total, $86.6 \%$ of the studied participants were 35 years old or less. About $24 \%$ of the HCWS had a working experience of 5 years or less. (Table-I) The HCWs' mean percent score for knowledge related to major childhood illnesses, common nutritional problems, and nutritional assessment methods in children under 5 years was found to be suboptimal. (Table-II) However, there was a significant difference in mean percent score between the two groups regarding their knowledge of nutritional assessment methods: 42.9 of nurses versus 22.2 of doctors $(p$-value $=0.001)$. (Table-II)

Table-I: Sociodemographic Information of Healthcare Workers

\begin{tabular}{|l|c|c|}
\hline $\begin{array}{c}\text { Sociodemographic } \\
\text { information }\end{array}$ & N & \% \\
\hline Age & 26 & 86.6 \\
\hline$\leq 35$ years & 4 & 13.3 \\
\hline$>35$ years & 9 & 13.4 \\
\hline Sex & 21 & 86.6 \\
\hline Male & 15 & 50 \\
\hline Female & 15 & 50 \\
\hline Profession & 22 & 74 \\
\hline Doctors & 8 & 26 \\
\hline Nurses & \\
\hline Type of d uty in Health Facility \\
\hline Direct patient care & 24 & 80 \\
\hline Others* & 6 & 20 \\
\hline Duration of work (years) & \multicolumn{1}{|l|}{} \\
\hline Doctors $\leq 5$ years & 4 & 26.6 \\
\hline Doctors $<5$ years & 11 & 73.3 \\
\hline Nurses &
\end{tabular}

Others*: Teaching, Research and Administration

However, the total mean percent score for practice related to breastfeeding was higher in nurses (65.4) than doctors (60.2) without significant difference 
(Table-II). The mean percent score for practice regarding recommendations to complementary feeding for an infant at 6 months was higher in doctors (48.7) than nurses (41.6), with no significant difference $(p=0.3)$. More than $73.3 \%$ of HCWs' reported correct practice regarding iron and folic acid supplementation to pregnant mothers'. (Table-III) However, less than a quarter $20 \%$ vs $13 \%$ of doctors vs nurses could report correct practice regarding Vitamin A supplementation for children U5 (Table-III). Although HCWs had a positive attitude towards characteristics and management of stunting in children under five; the total mean percent score for doctors' attitude (75.8 \pm 8.3$)$ was significantly higher versus nurses $(64.9 \pm 17.1)$ ( $\mathrm{p}$ value $=0.03)$. (Figure-I)

Table-II: Mean Percent for Knowledge and Practices of Healthcare Workers regarding Stunting in Children under Five

\begin{tabular}{|c|c|c|c|c|c|}
\hline \multirow[b]{2}{*}{ Variable } & \multicolumn{2}{|c|}{ Doctors $(n=15)$} & \multicolumn{2}{|c|}{ Nurses $(n=15)$} & \multirow[b]{2}{*}{ P-value } \\
\hline & $\begin{array}{l}\text { Mean } \\
\text { Percent } \\
\text { Score }\end{array}$ & $\begin{array}{l}\text { Standard } \\
\text { Deviation }\end{array}$ & $\begin{array}{l}\text { Mean } \\
\text { Percent } \\
\text { Score }\end{array}$ & $\begin{array}{l}\text { Standard } \\
\text { Deviation }\end{array}$ & \\
\hline \multicolumn{6}{|l|}{ Knowledge } \\
\hline $\begin{array}{l}\text { Major childhood } \\
\text { illnesses* }\end{array}$ & 48.2 & 22.0 & 46.5 & 21.7 & 0.70 \\
\hline $\begin{array}{l}\text { Common nutritional } \\
\text { problems** }\end{array}$ & 35.4 & 19.7 & 26.6 & 16.1 & 0.07 \\
\hline $\begin{array}{l}\text { Nutritional assessment } \\
\text { methods*** }\end{array}$ & 22.2 & 12.7 & 42.9 & 23.0 & $\leq 0.001$ \\
\hline \multicolumn{6}{|c|}{ Practices regarding mother's Health Education } \\
\hline $\begin{array}{l}\text { To overcome the } \\
\text { problem of malnutrition } \\
\text { in children }\end{array}$ & 53.1 & 17.3 & 41.13 & 25.3 & 0.02 \\
\hline $\begin{array}{l}\text { Barriers in the health } \\
\text { education of mothers } \\
\text { of children }\end{array}$ & 47.6 & 22.4 & 31.2 & 24.6 & 0.01 \\
\hline $\begin{array}{l}\text { Components of } \\
\text { sanitation to prevent } \\
\text { malnutrition }\end{array}$ & 44.3 & 25.8 & 52.6 & 28.6 & 0.50 \\
\hline $\begin{array}{l}\text { To counsel the mother } \\
\text { about her own health. }\end{array}$ & 53.4 & 25.0 & 33.2 & 22.1 & $\leq 0.001$ \\
\hline $\begin{array}{l}\text { Total mean percent } \\
\text { score }\end{array}$ & 46.7 & 16.0 & 40.8 & 18.6 & 0.03 \\
\hline \multicolumn{6}{|c|}{ Practice related to breastfeeding } \\
\hline $\begin{array}{l}\text { Reccomendation for the } \\
\text { start of breastfeeding }\end{array}$ & 13 & 86.6 & 14 & 93.3 & 0.23 \\
\hline $\begin{array}{l}\text { Recommendation for } \\
\text { exclusive breastfeeding }\end{array}$ & 11 & 73.3 & 9 & 60 & 0.03 \\
\hline $\begin{array}{l}\text { Recommendation for } \\
\text { breastfeeding continued } \\
\text { with food }\end{array}$ & 8 & 53.3 & 9 & 60 & 0.12 \\
\hline $\begin{array}{l}\text { Total mean percent } \\
\text { score }(\mathrm{MPS} \pm \mathrm{SD})\end{array}$ & \multicolumn{2}{|c|}{$60.2 \pm 25.2$} & \multicolumn{2}{|c|}{$65.4 \pm 20.9$} & 0.32 \\
\hline
\end{tabular}

*ARI, Diarrhea, Nutritional problems ** Iron DeficiencyAnemias, PEM, Iodine Deficiency Disorders and Ricketts

***Anthropometric assessment, Biochemical parameters, Clinical
The total mean percent score for doctors' and nurses' practice regarding health education of mothers was suboptimal; below 50 (Table-II). More than $80 \%$ of HCWs gave correct recommendations for the start of breastfeeding in infants.

Table-III: Mean Percent for Practices on weaning and micronutrient supplementation of Healthcare Workers regarding Stunting in Children under Five

\begin{tabular}{|c|c|c|c|c|c|}
\hline \multirow{2}{*}{ Variable } & \multicolumn{2}{|c|}{$\begin{array}{c}\text { Doctors } \\
(n=15)\end{array}$} & \multicolumn{2}{|c|}{ Nurses $(n=15)$} & \multirow{2}{*}{$\begin{array}{c}\mathbf{P} \\
\text { value }\end{array}$} \\
\hline & \begin{tabular}{|c|} 
Mean \\
Percent \\
Score
\end{tabular} & $\begin{array}{l}\text { Standard } \\
\text { Deviation }\end{array}$ & \begin{tabular}{|c|} 
Mean \\
Percent \\
Score
\end{tabular} & $\begin{array}{l}\text { Standard } \\
\text { Deviation }\end{array}$ & \\
\hline \multicolumn{6}{|l|}{ Practice related to weaning } \\
\hline $\begin{array}{l}\text { Recommendations to } \\
\text { complementary feeding } \\
\text { for an infant at } 6 \text { months }\end{array}$ & 48.7 & 22.7 & 41.6 & 31.2 & 0.37 \\
\hline $\begin{array}{l}\text { Type of counseling with } \\
\text { mothers on preparing } \\
\text { complementary foods }\end{array}$ & 41.0 & 19.1 & 35.7 & 25.8 & 0.55 \\
\hline \multicolumn{6}{|c|}{ Practice regarding micronutrient supplementation } \\
\hline $\begin{array}{l}\text { Micronutrients } \\
\text { supplementation for } \\
\text { women during pregnancy }\end{array}$ & 15 & 100 & 11 & 73.3 & \\
\hline $\begin{array}{l}\text { Vitamin A } \\
\text { supplementation for } \\
\text { children under five }\end{array}$ & 3 & 20 & 2 & 13.3 & \\
\hline $\begin{array}{l}\text { Zinc recommendation in } \\
\text { children with diarrhea }\end{array}$ & 5 & 33.3 & 10 & 66.6 & \\
\hline
\end{tabular}

Figure-I: Mean Percent of Healthcare Worker's Attitude regarding Stunting in Children under Five

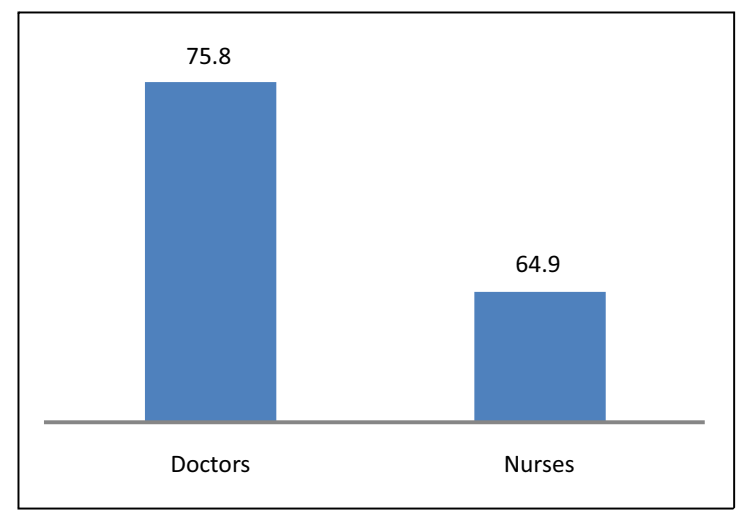

\section{Discussion}

In our study, among the respondent's majority were female $(86.6 \%)$, this finding concurs with the 
observation in a similar study conducted at PHC facilities in South Africa, in which the majority of participants were females $(91.7 \%)$ compared with male participants. ${ }^{12}$ Majority of the doctors $(86.6 \%)$ were about 35 years old and $60 \%$ of them had work experience of 5 years or less. This is in agreement with a study conducted at PHC facilities in Abbottabad, Pakistan, in which the majority of physicians were 38 years and they had 2.53 years of experience of working in BHU. ${ }^{13}$ Nevertheless, more than $50 \%$ of the nurses in our study were 35 years old or above and $87 \%$ of them had a working duration of more than 5 years.

The mean percent score of HCWs' knowledge was about 50 regarding major childhood illnesses, common nutritional problems, and nutritional assessment methods in children under 5 , in our study. This is attributed to inadequate medical nutrition education in undergraduate and postgraduate studies, and due to a lack of implementing practical part of it. A similar level of response about nutritional knowledge $(50 \%)$ was reported by a study conducted in Jeddah, Saudi Arabia, in which the majority of Saudi physicians found it difficult to perform nutritional management of patients due to their inadequate nutrition knowledge and skill. ${ }^{14}$ Also in another study it was found that the majority of HCWs had poor knowledge and skill, in nutrition topics and $3 / 4$ of the respondents had a positive attitude towards nutritional issues. ${ }^{15} \mathrm{HCW}$ face difficulty in child nutrition management due to a lack of adequate nutrition knowledge and practical nutrition training. Nonetheless, a core nutrition curriculum in Public health and Community Medicine has been introduced, which is likely to strengthen the medical nutrition practice.

In our study, nurses scored significantly higher mean percent knowledge score than doctors ( $\leq$ 0.001) in 'Nutritional Assessment Methods'. This could be due to the majority of nurses $(73.3 \%)$ having working experience of $>5$ years, and performing nutritional assessment of children on daily basis at PHCs. This is consistent with the findings of a study at Pediatric Emergency at Kenyatta Hospital (2018), in which $96.8 \%$ of nurses did the nutritional assessment of the children while the performance by doctors was poor $(78.6 \%){ }^{16}$ The total mean percent score for the practice of doctors' and nurses' in health education of mothers was suboptimal; 46.7 and 40.8 respectively in our study. It could be due to the barriers including 'Mother's cultural issues', 'lack of HCWs' trainings' and 'lack of HCWs' knowledge' identified by HCWs in the health education of mothers in the current study. This observation concurs with the finding in the study carried out at PHC facilities in South Africa (2017), in which all HCWs felt that health promotion messages are important, but only $51 \%$ of them could convey health messages during consultations. ${ }^{12}$

According to WHO, breastfeeding should be initiated within one hour of birth. Among South Asian countries, Pakistan has the lowest breastfeeding rate (29\%), ${ }^{17}$ and according to Pakistan Demography and Health Survey (PDHS) (2017 -18), the Exclusive Breastfeeding (EBF) rate is also worst $(37 \%){ }^{18}$ In Pakistan, Baby-Friendly Hospital Initiative (BFHI) was started in 1992 for the training of staff on breastfeeding practices and policies. Counseling under the BFHI improved breastfeeding practices up to $98.97 \%$ in baby-friendly hospitals. ${ }^{19}$ In the current study, nurses had an overall higher mean percent score (64.5) regarding breastfeeding practice as compared to doctors (60.2), which could be due to the majority $(87 \%)$ of nurses' job description, more working experience, and being 35 years old or above. This is in contrast to findings in another study, 'KAP of the medical staff regarding Breastfeeding management' (2019), where mean percent scores of physician practice (62.90) were significantly higher than that of nursing staff (49.7) regarding breastfeeding. ${ }^{20}$ Moreover, in the current study more than $86 \%$ of doctors and nurses gave correct recommendations for the start of breastfeeding in infants which is in agreement with a study at the tertiary care hospital of Karachi (2016), where $91.5 \%$ of the doctors supported breastfeeding to be started within half an hour of birth. ${ }^{21}$

Diarrhea and acute respiratory infections are the leading two causes of death among under-five. ${ }^{22}$ Exclusive breastfeeding prevents growth faltering and protects against childhood infections. ${ }^{23}$ However, regarding correct recommendations for duration of EBF, in our study, the proportion $(73.3 \%)$ of doctors was higher versus $(60 \%)$ of nurses ( $p$ value $<0.05$ ), supported by higher mean percent attitude score of doctors towards EBF comparing to nurses in our study. This is supported by a finding in a study conducted to 'Assess the KAP of mothers in South Indian hospital towards breastfeeding 'in which mothers relied on doctors as their preferred counselor $(87.5 \%){ }^{24}$ However, the proportion of doctors reporting 'EBF recommendation for the first 
6 months of life $(73.3 \%)$ and 'duration of breastfeeding as 2 years $(53.3 \%)$ was lower in the present study than that reported $(97 \%)$ and $(82.5 \%)$ respectively in another study. ${ }^{21}$ Moreover, only $52.9 \%$ of doctors and $40.2 \%$ of nurses advised breastfeeding to be continued for 2 years in another study (2018). ${ }^{25}$ Less than $70 \%$ of 6 to 8 months old children received solid or semisolid foods according to PDHS (2017 -18). In the current study, reported practice on 'introducing solid foods at 6 months' though suboptimal, was higher in doctors than nurses, with no significant difference; the reason being the majority of doctors were fresh graduates retaining their undergraduate knowledge, and their positive attitude towards weaning. This observation is in agreement with the findings of another study at pediatric departments, Alexandria in which the proportion of doctors $(58.8 \%)$ was higher than nurses $(25.7 \%)$ in their opinion regarding children should be weaned on cow's milk for better growth after 6 months. ${ }^{17}$

According to PDHS (2017 -18), despite the fact $75 \%$ of children (6-59 months of age) were given vitamin A supplements, we found in our study that less than a quarter of HCWS could report recommended practice regarding Vitamin A supplementation for children. This is in contrast to a study where it was observed that $93 \%$ of HCWs showed knowledge for correct regimens for vitamin A supplementation and Road to Health Booklets were completed adequately for vitamin A supplementation (94.6\%). ${ }^{12}$ Moreover, more than $73.3 \%$ of HCWs reported correct practice regarding ' iron and folic acid supplementation to pregnant mothers'. This is similar to a study in which all PHC pediatricians followed national standards for anemia and prescribed iron in prophylactic doses. $^{26}$

\section{Conclusion}

This study showed that Healthcare Workers had sub-optimal knowledge regarding stunting. There was no significant difference between doctors' and nurses' KAP in most of the terms. Although, they had a positive attitude towards stunting management, yet they showed sub-optimal practices in most of the items. Inadequate undergraduate nutrition curricula, lack of practical nutrition training, and the barriers in health education of caregivers reported by HCWs could be the reason so that inadequate knowledge could not be translated into accurate and useful counseling to mothers during nutrition-related services to children under five at PHCs. Since knowledge is power, and health facilities could invest this power to improve the quality of services, as caregivers empowered by knowledge ensure optimal infant feeding. On the job and continuous practical training of $\mathrm{HCWs}$ is mandatory for refreshing and updating their knowledge and skills. The undergraduate curriculum of medical and paramedical students, as well as postgraduate medical students, should contain detailed knowledge about the optimal feeding patterns of children. More research is required to identify gaps in HCWs' nutrition knowledge and training and to determine if that knowledge is being translated into accurate and useful counsel to mothers during the ANC visit.

Authors Contribution: SZ: Design of work and Drafting.RS: Design of work, Acquisition and analysis of data and Drafting. SA: Conception of work and Revising. SA: Interpretation of data and drafting. UT: Conception of work and drafting.

All authors critically revised and approve its final version.

Conflict of Interest: Author has declared no conflict of interest.

Sources of Funding: The source of funding was self. Disclaimer: None

\section{References}

1. UNICEF. The State of the World's Children 2019-Growing Well in a Changing World. 2019.

2. UNICEF. Levels and trends in child malnutrition UNICEF-WHO-World Bank Group joint child malnutrition estimates. 2015.

3. Unicef. Child Nutrition. Available at https:/www.unicef.org/media/60806/file/SOWC-2019.pdf (Accessed: 5 July; 2019)

4. Das JK, Achakzai ABK, Bhutta ZA. Stop stunting: Pakistan perspective on how this could be realized. Maternal \& child nutrition. 2016;12(Suppl 1):253

5. Organization WHO. Levels and trends in child malnutrition: key findings of the 2018 edition. World Health Organization, 2018.

6. Malik SM, Bhutta ZA. Reform of primary health care in Pakistan. The Lancet. 2018; 392(10156):1375-7.

7. Asim M, Nawaz Y. Child malnutrition in Pakistan: evidence from literature. Children. 2018; 5(5):60. 
8. Akseer N, Vaivada T, Rothschild O, Ho K, Bhutta ZA. Understanding multifactorial drivers of child stunting reduction in Exemplar countries: a mixed-methods approach. The American journal of clinical nutrition. 2020; 112(Supplement_2):792S-805S.

9. Sjarif DR, Yuliarti K, Wahyuni LK, Wiguna T, Prawitasari T, Devaera Y, et al. Effectiveness of a comprehensive integrated module using interactive lectures and workshops in understanding and knowledge retention about infant feeding practice in fifth year medical students: a quasi-experimental study. BMC medical education. 2016; 16(1):1-9.

10. Omer AM, Haile D, Shikur B, Macarayan ER, Hagos S. Effectiveness of a nutrition education and counseling training package on antenatal care: a cluster randomized controlled trial in Addis Ababa. Health Policy and Planning. 2020;35(Supplement_1):i65-i75.

11. $\mathrm{Hea} 1 \mathrm{th} \quad \mathrm{syst}$ e m . A v a i $1 \mathrm{ab} l \mathrm{e}$ at:http://www.emro.who.int/pak/programmes/primarya-secondary-health-care.html (Accessed: 25 Sep; 2019)

12. Blaauw R, Daniels L, Du Plessis LM, Koen N, Koornhof HE, Marais ML, et al. Assessing the utilization of a child health monitoring tool. South African Journal of Child Health. 2017; 11(4):174-9.

13. Shah SM, Zaidi S, Ahmed J, Rehman SU. Motivation and retention of physicians in primary healthcare facilities: a qualitative study from Abbottabad, Pakistan. International journal of health policy and management. 2016; 5(8):467.

14. Alkhaldy AA, editor Nutritional knowledge and selfreported nutritional practice against malnutrition among physicians in Jeddah, Saudi Arabia. Healthcare; 2019: Multidisciplinary Digital Publishing Institute.

15. Wondimagegne, Zelalem\&Shele, Anteneh. Knowledge, attitude and practice towards malnutrition among health care workers in Hawassa City, Southern Ethiopia. Academic Research International.2015: 1: 1-8.

16. Ndiema, Nelly \&Mutai, Joseph Makworo, Drusilla. Nutritional Assessment Practices among Health Care Workers at the Pediatric Emergency Unit at Kenyatta National Hospital. Pediatrics \& Therapeutics. . 2018. 08. 10.4172/2161-0665.1000348.
17. Khaliq A, Qamar M, Hussaini SA, Azam K, Zehra N, Hussain M, et al. Assessment of knowledge and practices about breastfeeding and weaning among working and nonworking mothers. Journal of the Pakistan Medical Association. 2017;67(3):332-8.

18. National Institute of Population Studies - NIPS/Pakistan and ICF. 2019. Pakistan Demographic and Health Survey 201718.

19. Khan, Mahjabeen, Akram, Durre. Effects of baby-friendly hospital initiative on breast-feeding practices in Sindh. JPMA. The Journal of the Pakistan Medical Association.2013: 63; 756-9.

20. Weshahy HMF, Rashad MM, Abul-fadl M, Mohammed AAA. Knowledge, Attitude, and Practice among Medical Staff towards Breastfeeding Management. Al-Azhar Journal of Pediatrics. 2019; 22(4):600-16

21. Ehsan S, Ghori U, Agha F. Knowledge, attitude and practice of medical practitioners regarding breastfeeding: a study at a tertiary care hospital of Karachi. Pak J Med Dent. 2016; 5(1):36-40.

22. Liu L, Oza S, Hogan D, Chu Y, Perin J, Zhu J, et al. Global, regional, and national causes of under- 5 mortality in 2000-15: an updated systematic analysis with implications for the Sustainable Development Goals. The Lancet. 2016; 388(10063):3027-35.

23. Kamenju P, Liu E, Hertzmark E, Spiegelman D, Kisenge RR, Kupka R, et al. Complementary feeding and diarrhea and respiratory infection among HIV-exposed Tanzanian infants. Journal Acquired Immune def Synd. 2017; 74(3):265.

24. Chinnasami B, Sundar S, Kumar J, Sadasivam K, Pasupathy S. Knowledge, attitude and practices of mothers regarding breastfeeding in a South Indian Hospital. Biomedical and Pharmacology Journal. 2016; 9(1):195-9.

25. Shaw SC, Devgan A. Knowledge of breastfeeding practices in doctors and nurses: A questionnaire-based survey. Medical Journal Armed Forces India. 2018;74(3):217-9.

26. Sguassero Y, Guerrero MM, Romero M. The perspective of primary health care pediatricians regarding childhood anemia and iron supplementation. Arch Argent Pediatr. 2018; 116(1):21-7. 